\title{
Macro-fungal diversity of Bukit Timah Nature Reserve, Singapore
}

\author{
S.M.L. Lee \\ Singapore Botanic Gardens, National Parks Board, \\ 1 Cluny Road, 259569 Singapore \\ Serena_Lee@nparks.gov.sg
}

\begin{abstract}
The Bukit Timah Nature Reserve is an extremely important type locality for many species of macrofungi, especially for those collected by Edred John Henry Corner between 1929 and 1945 and later described by him. There has been little work done on the fungi of Singapore in recent years and much remains to be done. Current efforts to curate the fungal collection at Singapore Botanic Gardens are discussed, a new collecting programme is highlighted, and the very long way to go before we have a decent understanding of macrofungal diversity of Bukit Timah and the rest of Singapore is emphasised.
\end{abstract}

Keywords. Fungal biodiversity, macrofungi in Singapore, fungal type specimens

\section{Introduction}

Fungi form a network of mycelia that can extend for thousands of kilometres below the ground surface, connecting life and communities in forest soils (Babikova et al., 2013; Simard, 2018). As agents of decomposition (Schwarze et al., 2000), partners in ectomycorrhizal relationships (Watling \& Lee, 1995; Simard et al., 1997; Watling \& Lee, 1998) and arbuscular mycorrhizal relationships (Jacott et al., 2017; Lanfranco et al., 2018; Mathieu et al., 2018), they are the heart of nutrient recycling in every forest.

A current estimate of the world's fungal taxa is between 2.2 to 3 million (Hawksworth \& Lücking, 2017). The Checklist of Literature on Malaysian Macrofungi (Lee et al., 2008), which includes Singapore, estimates that $70 \%$ of the larger fungi in this region have yet to be discovered or described. The lack of research on the fungi of Singapore, including the macrofungi, is evident from the fact that Corner's monographic works (Corner, 1966, 1968, 1970, 1972) are often the only ones available for the region.

An annotated checklist of the macrofungi recorded from Bukit Timah has been compiled by Tham \& Watling (2017a), largely from a synthesis of publications by E.J.H. Corner based on his collections made in Singapore from 1929 to 1945. Corner's publications have been listed by Watling \& Ginns (1998), and a further review of Corner's mycological work was published by Watling (2007). Corner was extremely prolific, having authored 1504 fungal names (data from Index Fungorum, compiled by Kirk \& Cooper, 2016). Casual observations by later mycologists have added to the Bukit Timah list (e.g., Tham \& Chan, 2009; Tham \& Watling, 2010). 
Tham \& Watling (2017a) included 230 taxa in their list of the fungi of Bukit Timah Nature Reserve, of which Bukit Timah is the type locality for 98 or $42 \%$ of these taxa. Accompanying Tham \& Watling's (2017a) list for Bukit Timah there are also parallel checklists for the MacRitchie-Peirce Reservoir (spelt as 'Pierce' in Tham \& Watling, 2017b) sector of the Central Catchment Nature Reserve (Tham \& Watling, 2017b), for Mandai-Seletar (Tham \& Watling, 2017c) and for the Singapore Botanic Gardens (Tham \& Watling, 2017d), making comparisons between localities possible for the first time. There are two earlier checklists of fungi for Singapore, by Chipp (1921), with specimen citations for collections in SING, and Turner et al. (1994), which is in a simple format with no specimen citations.

\section{The SING fungarium}

The Herbarium of the Singapore Botanic Gardens (SING) has fungal collections dating back as far as 1841 but well-collected, labelled and named specimens only began with H.N. Ridley's collections from 1889 onwards. Demoulin (2011) gave an overview of the historical importance of the mycological collection in Singapore, and some of the problems linked to Corner's material were discussed by him in the light of subsequent studies made in both Singapore and Edinburgh. Demoulin (2011) considered the polypore collection in Singapore a valuable resource for studying any geographical variation of fungal floras in the Malesian region and a unique tool for examining any temporal change in this flora, given the continuity of collections in the island since H.N. Ridley. Due to the lack of fungal expertise in SING over many years, and other pressing needs, the collection of fungi has long been left uncurated, with much material unnamed, leading to these collections not being included in works such as Tham \& Watling (2017a). Curation and databasing of the material is still on-going.

There is no material in SING of many of the species described by Corner, including the type collections. This makes it hard to identify new material collected. It also reduces the incentives for researchers to visit and consult the SING collection and thereby improve the naming and curation of the collection. Most of Corner's type specimens are lodged at the Herbarium of the Royal Botanic Garden, Edinburgh (E) (Watling \& Ginns, 1998; Watling, 2001; Watling, pers comm., 2016.).

\section{Methods of collection and identification}

The last staff member in SING with a mycological interest was Chang Kiaw Lan who retired in 1987 (Wong, 2003). Between 1987 and fairly recently, only around 50 specimens of macrofungi were collected. Therefore, a programme to collect and better document the macrofungi of Singapore has been launched.

Collection involves removing the entire basidiome by means of wedging a spade approximately two inches $(5 \mathrm{~cm})$ under the basidiome from the level of the substrate (where applicable). A note of the substrate that the fungus was on is made 
and images of the basidiome in its natural environment are captured. Vouchers are brought back to the herbarium for further processing. This includes making spore prints and the application of chemical reagents if necessary. A small portion of the fungus is placed in silica gel for future DNA sequencing. Basidiomes are air dried in a food dehydrator at no more than $40^{\circ} \mathrm{C}$. Once dried, they are placed in ziplock bags, to avoid rehydration, along with accompanying pictures and the collection label. For more information on fungal processing see Buyck et al. (2010) and Halling (1996). Collections have also been made by various colleagues who chanced upon basidiomes in their line of work.

Specimens were initially identified using Largent (1986), Largent et al. (1980) and Largent \& Baroni (1988). When an identification could not be made, international fungal identification professionals and amateurs were engaged on social media platforms. This has been proven largely successful in identification to genus level. Once placed in a genus, identification to species level was done using the relevant literature (e.g. Corner \& Bas, 1962; Horak, 1980; Zanuddin et al. 2010; Thi et al., 2011; Lee et al., 2012; Lee, 2017).

\section{Initial findings}

The effort in fungal research for Bukit Timah Nature Reserve is far behind that of higher plants and many other groups of organisms and this paper is by way of an introduction to the task ahead rather than a collation of research findings. However, it is to be noted that many common species found on Bukit Timah, such as Pycnoporus sanguineus (L.) Murrill, Schizophyllum commune Fr., Microporus xanthopus (Fr.) Kuntze, Favolaschia manipularis (Berk.) Teng and Scleroderma sinnamariense Mont., are not included in the checklist by Tham \& Watling (2017a) as being recorded there. Figs. 1-3 include photographs of 17 species of which only six are included in Tham \& Watling (2017a). Some of these species have been photo-documented by Hadzlinda Samri, an NParks staff member, and some are from collections lodged at the Singapore Herbarium (SING).

As well as the new collections being made, from the recent curation and databasing effort mentioned above, many fungi not previously recorded for Bukit Timah have come to light. These will be published at a later date when curation and databasing of the collection have been completed.

In addition, there remain a great many specimens from Bukit Timah identified only to generic level or only to family from the Agaricaceae, Boletaceae, Entolomataceae, Lyophyllaceae, Marasmiaceae, Polyporaceae, Xylariaceae and many others. Considerably more basic research will be needed in order to name these fungi and it is highly likely that these collections include many new records for Bukit Timah and Singapore and it is also likely that there are several undescribed species. The task of identifying this material is made rather more difficult because so many species have extremely wide and disjunct distributions, thereby greatly widening the scope of literature and other collections that must be consulted. 


\section{Conclusions}

Fungi are a fascinating yet neglected group of organisms that require much greater research effort in order to understand better the overall biodiversity of Singapore. To this end the staff of Singapore Botanic Gardens, along with colleagues from the National Parks Board, will continue to collect, identify and catalogue fungi, including from Bukit Timah Nature Reserve. While the published checklists indicate a known flora of more than 230 fungal taxa from the reserve, new collections as well as the re-examination and curation of past collections in SING indicate that the real wtotal must be considerably higher. The staff of the National Parks Board and SING Herbarium are open to research collaboration with mycologists around the world. Fig. 1-3, with just a selection of the fungi that could be identified, should whet the appetite of those wanting to know more and join this research effort.

ACKNOWLEDGEMENTS. I would like to thank my NParks colleagues especially Aung Thame, Bazilah Ibrahim, Derek Liew, Ho Boon Chuan, Jana Leong-Škorničková, Lua Hock Keong, Ng Xin Yi, Paul Leong and many others who have taken the trouble to bring in specimens when they were on various other surveys. I also thank Christina Soh who helped source out-of-print references that were needed, and David Middleton for his comments on the manuscript. 

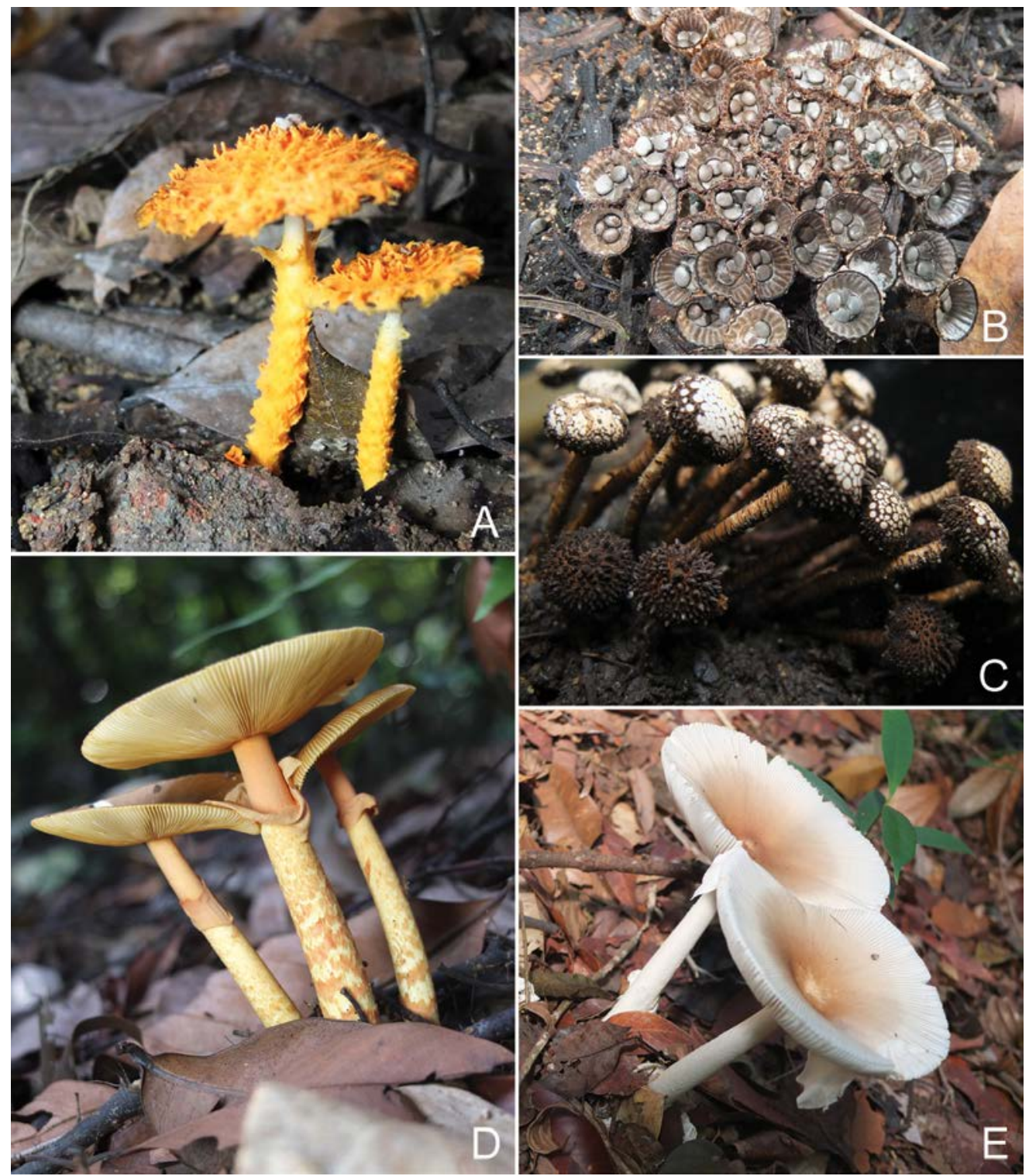

Fig. 1. A. Agaricaceae Agaricus crocopeplus (SL1164); B. Agaricaceae Cyathus striatus (SL1103); C. Agaricaceae Tulostoma exasperatum (Lee, M. 17.1.5); D. Amanitaceae Amanita similis (SL1159); E. Amanitaceae Amanita princeps (SL1160). (Photos: S.M.L. Lee) 


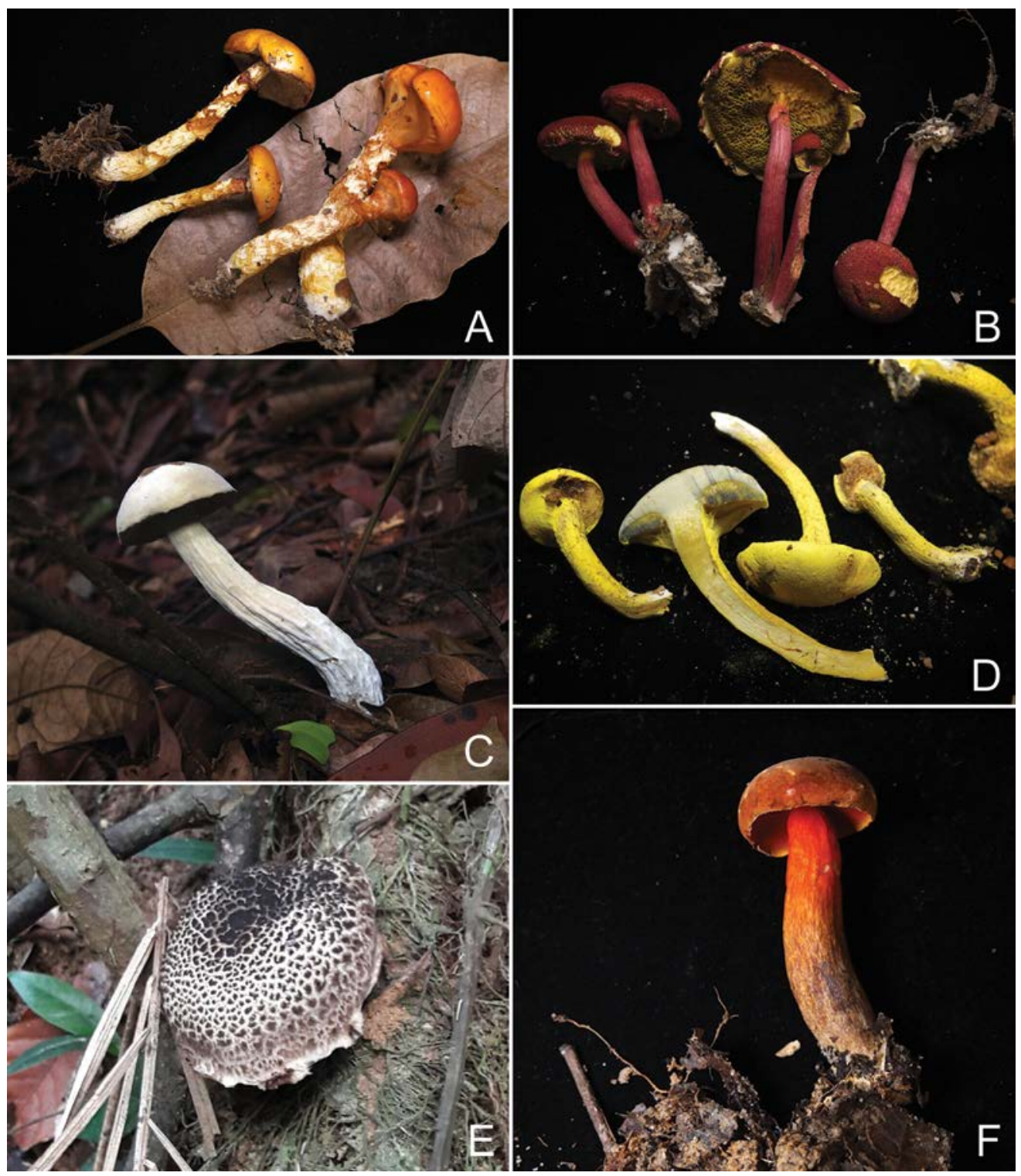

Fig. 2. All Boletaceae. A. Austroboletus mucosus (SL1178); B. Boletellus emodensis (SL1184); C. Pseudoaustroboletus valens (SL1123); D. Pulveroboletus icterinus (SL1209); E. Strobilomyces velutipes (SL1167); F. Tylopilus cervinicoccineus (SL1237). (Photos: A-D \& F, S.M.L. Lee; E, D. Liew) 

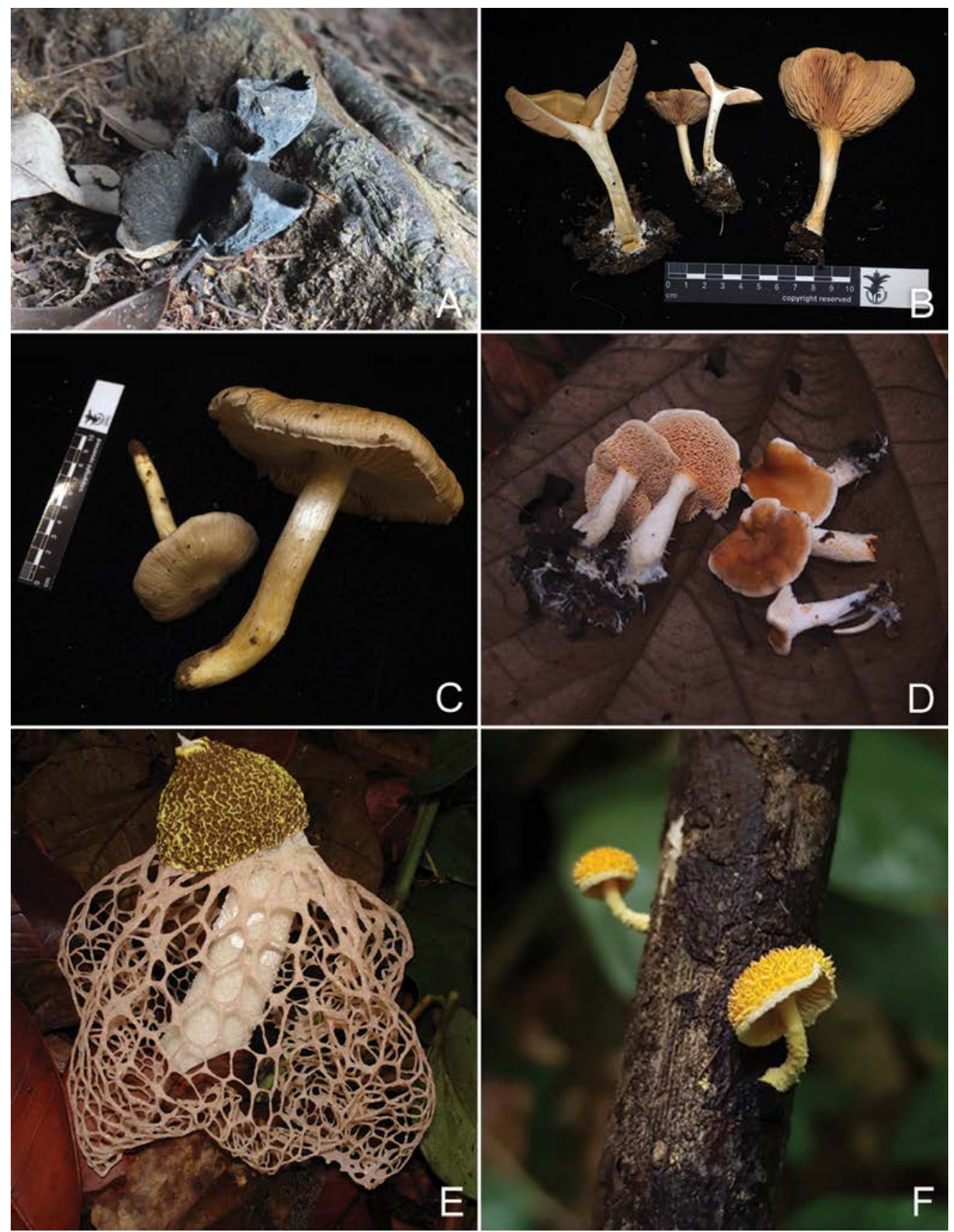

Fig. 3. A. Cantharellaceae Cantharellus cornucopioides (SL1162); B. Entolomataceae Entoloma flavidum (SL1168); C. Entolomataceae Entoloma pallidoflavum (SL1115); D. Hydnaceae Hydnum elatum (SL1121); E. Phallaceae Phallus multicolor (SL1238); F. Physalacriaceae Cyptotrama asprata (SL1233). (Photos: A-D \& F, S.M.L. Lee; E, J. Leong-Škorničková) 


\section{References}

Babikova, Z., Gilbert, L., Bruce, T.J., Birkett, M., Caulfield, J.C., Woodcock, C., Pickett, J.A. \& Johnson, D. (2013). Underground signals carried through common mycelial networks warn neighbouring plants of aphid attack. Ecol. Lett. 16(7): 835-843.

Buyck, B., Læssøe, T., Meyer, M. \& Hofstetter, V. (2010). Collecting the neglected kingdom: Guidelines for the field mycologist with emphasis on the larger fungi. In: Eymann, J, Degreef, J., Häuser, C., Monje, J.C., Samyn, Y. \& Van den Spiegel, D. (eds) Manual on field recording techniques and protocols for All Taxa Biodiversity Inventories and Monitoring, vol. 8, pp. 308-330. Brussels: Belgian National Focal Point to the Global Taxonomy Initiative.

Chipp, T.F. (1921). A list of the fungi of the Malay Peninsula. Gard. Bull. Straits Settlem. 2: $311-418$.

Corner, E.J.H. (1966). Monograph of cantharelloid fungi. Ann. Bot. Mem. 2: 1-255.

Corner, E.J.H. (1968). A monograph of Thelephora (Basidiomycetes). Beih. Nova Hedwigia 27: $1-110$.

Corner, E.J.H. (1970). Supplement to: A monograph of Clavaria and allied genera. Beih. Nova Hedwigia 33: 1-299

Corner, E.J.H. (1972). Boletus in Malaysia. Singapore and Malaya: Government Printing Office.

Corner, E.J.H. \& Bas, C. (1962). The genus Amanita in Singapore and Malaya. Persoonia 2(3): 241-304.

Demoulin, V. (2011). The study of larger basidiomycetes, especially polypores, in the Malaysian region and the role of the Singapore Botanic Gardens. Gard. Bull. Singapore 63: 175-188.

Halling, R.E. (1996). Recommendations for collecting mushrooms for scientific study. In: Alexiades, M.N. \& Sheldon, J.W. (eds) Selected Guidelines for Ethnobotanical Research: A field manual, pp. 135-141. The New York Botanical Garden Press, Bronx.

Hawksworth, D.L. \& Lücking, R. (2017). Fungal Diversity Revisited: 2.2 to 3.8 Million Species. Microbiol. Spectr. 5(4) 1-17.

Horak, E. (1980). Entoloma (Agaricales) in Indomalaya and Australasia. Beih. Nova

Hedwigia 65: 1-352.

Jacott, C.N., Murray, J.D. \& Ridout, C.J. (2017). Trade-offs in arbuscular mycorrhizal symbiosis: disease resistance, growth responses and perspectives for crop breeding. Agronomy 7(4): 75[1-18]. doi:10.3390/agronomy7040075

Kirk, P. \& Cooper, J. (Continuously updated). Index Fungorum. http://www.indexfungorum. org/. Accessed 2 Jul. 2016.

Lanfranco, L., Fiorilli, V. \& Gutjahr, C. (2018). Partner communication and role of nutrients in the arbuscular mycorrhizal symbiosis. New Phytol. 220(4): 1031-1046. doi:10.1111/ nph. 15230

Largent, D.L. (1986). How to Identify Mushrooms to Genus I: Macroscopic Features. Eureka, USA: Eureka Printing Company.

Largent, D.L., Johnson, D. \& Watling, R. (1980). How to Identify Mushrooms to Genus III: Microscopic Features. Eureka, USA: Eureka Printing Company.

Largent, D.L. \& Baroni, T.J. (1988). How to Identify Mushrooms to Genus VI: The Modern Genera. Eureka, USA: Mad River Press.

Lee, S.S. (2017). A field guide to the larger fungi of FRIM, research pamphlet no. 135. Kepong, Malaysia: Forest Research Institute Malaysia. 
Lee, S.S., Horak, E., Alias, S.A., Thi, B.K., Nazura, Z., Jones, E.B.G. \& Nawawi, A. (2008). Checklist of Literature on Malaysian Macrofungi. https://www.mybis.gov.my/pd/70. Accessed 21 May 2016.

Lee, S.S., Alias, S.A., Jones, E.B.G., Zainudin, N. \& Chan, H.T. (2012). Checklist of Fungi of Malaysia. Research Pamphlet No. 132. Kepong, Malaysia: Forest Research Institute Malaysia.

Mathieu, S., Cusant, L., Roux, C. \& Corradi, N. (2018). Arbuscular mycorrhizal fungi: intraspecific diversity and pangenomes. New Phytol. 220(4): 1129-1134. doi:10.1111/ nph. 15275

Schwarze, F.W.M.R., Engels, J. \& Mattheck, C. (2000). Fungal Strategies of Wood Decay in Trees. Berlin: Springer-Verlag.

Simard S.W. (2018). Mycorrhizal Networks Facilitate Tree Communication, Learning, and Memory. In: Baluska F., Gagliano M., Witzany G. (eds) Memory and Learning in Plants. Signaling and Communication in Plants, pp.191-213. Champaign, Illinois: Springer.

Simard, S.W., Perry, D.A., Jones, M.D., Myrold, D.D., Durall, D.M. \& Molina, R. (1997). Net transfer of carbon between ectomycorrhizal tree species in the field. Nature 388(6642): 579-582.

Tham, F.Y. \& Chan, T.Y. (2009). A record of gregarious fruiting of blue Entoloma fungi at Bukit Timah Nature Reserve. Nat. Singapore 2: 121-124.

Tham, F.Y. \& Watling, R. (2010). Sighting of Pulveroboletus frians (Basidiomycetes: Boletales) at Bukit Timah Nature Reserve. Nature in Singapore 3: 39-43.

Tham F.Y. \& Watling, R. (2017a). Annotated checklist of macrofungi recorded from Singapore: Bukit Timah. Singapore.

Tham F.Y. \& Watling, R. (2017b). Annotated checklist of macrofungi recorded from Singapore: MacRitchie-Pierce. Singapore.

Tham F.Y. \& Watling, R. (2017c). Annotated checklist of macrofungi recorded from Singapore: Mandai-Seletar. Singapore.

Tham F.Y. \& Watling, R. (2017d). Annotated checklist of macrofungi recorded from Singapore: Singapore Botanic Gardens. Singapore.

Thi, B.K., Lee, S.S., Zanuddin, N. \& Chan, H.T. (2011). A Guidebook to the Macrofungi of Fraser's Hill. Siri Alam dan Rimba No. 14. Kepong, Malaysia: Forest Research Institute Malaysia.

Turner, I.M., Tan, T.K. \& Metcalfe, D.J. (1994). Fungi: Zygomycetes, Ascomycetes, Basidiomycetes and Deuteromycetes. In: Wee, Y.C. \& Ng, P.K.L. (eds) A first look at biodiversity in Singapore. Singapore: National Council on the Environment.

Watling, R. (2001). Edred John Henry Corner (1906-1996): a pioneer in tropical mycology. Mycol. Res. 105(12): 1533-1536.

Watling, R. (2007). A mine of information and treasury of specimens: Corner's mycological legacy. In: Jones, E.B.G., Hyde, K.D. \& Sabaratnam, V. (eds) Malaysian Fungal Diversity, pp. 25-39. Kuala Lumpur: Mushroom Research Centre, University of Malaya and Ministry of Natural Resources and Environment Malaysia.

Watling, R. \& Ginns, J. (1998). E. J. H. Corner, 1906-1996. Mycologia 90(4): 732-737.

Watling, R. \& Lee, S.S. (1995). Ectomycorrhizal fungi associated with members of the Dipterocarpaceae in Peninsular Malaysia-I. J. Trop. For. Sci. 7(4): 657-669.

Watling, R. \& Lee, S.S. (1998). Ectomycorrhizal fungi associated with members of the Dipterocarpaceae in Peninsular Malaysia-II. J. Trop. For. Sci. 10(4): 421-430. 
Wong, K.M. (2003). Obituary: Dr Chang Kiaw Lan, 31 July 1927-14 August 2003. Gard. Bull. Singapore 55: 309-315.

Zanuddin, N., Lee, S.S., Chan, H.T. \& Thi, B.K. (2010). A Guidebook to the Macrofungi of Tasik Bera. Siri Alam dan Rimba No. 13. Kepong, Malaysia: Forest Research Institute Malaysia. 